\title{
Experimenting With 'Managing The Digital Enterprise' Open Courseware In The AIS Course
}

Carol M. Jessup (E-mail: jessup.carol@ uis.edu), University of Illinois at Springfield

\begin{abstract}
The experience of an AIS professor over two semesters in using an open courseware site, 'Managing the Digital Enterprise' is discussed. To keep this experiment from supplanting existing course requirements, integration with Webboard technology facilitated the efficient use of class time. Initial instructional design flaws related to random scheduling of online assignments and assessment concerns were overcome the following semester. In addition to describing the courseware site and companion instructor's guide, informal student feedback is provided.
\end{abstract}

\section{Introduction}

n May of 2001, an AIS educator who attended the AACSB International Management Education ECommerce Conference in Atlanta Georgia was first exposed to the concept of open courseware. This exposure took place during a plenary session entitled "Adopting 'Managing the Digital Enterprise', an On-line Resource for Teaching e-Commerce" presented by Michael Rappa. Professor Rappa, Distinguished Professor of Technology Management at the North Carolina State University in Raleigh, North Carolina, is the creator of one of the most widely used sites devoted to the teaching of electronic commerce. His course, Managing the Digital Enterprise is the first of its kind to adopt the open courseware model and to rely exclusively on web-based content. http://digitalenterprise.org/mrappa.html

There are several objectives of this article. An overview of open courseware in general, as well as the specific course site and online instructor's guide, is provided. Next a description of one AIS professor's experience using Webboard to integrate this curriculum within a face to face AIS course is discussed. Subsequent revision processes to overcome instructional design flaws during the second semester are detailed. Student feedback in the form of narrative comments is specified. Suggestions for future/alternative uses of the site within AIS courses are made. The article indicates that benefits of using 'Managing the Digital Enterprise' clearly merit the attention of AIS educators to investigate this useful, up-to-date, practical resource, which is available at no cost.

\section{Open Courseware}

The term "open courseware" refers to educational materials made publicly available for individual use without charge. Open courseware is open in all the following ways: all the time, across geographic, organizational, and national boundaries, to everyone with web access, to collaboration and change, and in using open architecture. "Open courseware follows in the age old tradition among scholars of sharing information to advance the frontier of knowledge. http://digitalenterprise.org/open_courseware.html

The OpenCourseWare (OCW) project was first announced in a press release in April 2001 by the president of Massachusetts Institute of Technology, Charles Vest. In his remarks, Vest acknowledged that "OCW looks counter-intuitive in a market driven world...it really is consistent with...the best about MIT. It is innovative. It expresses our belief in the way education can be advanced - by constantly widening access to information and by inspiring others to participate (MIT News, 2001). Many questions have been raised as to exactly what the initiative is

Readers with comments or questions are encouraged to contact the author via email. 
(Long, 2002). For example, some individuals mistakenly assumed that MIT was going to put all of its courses online; others thought that open courseware was equivalent to an online course. OCW is not an online course; rather is a process intended to make MIT course materials free and available; it is not the courses themselves that are available, but rather the course contents (TechTalks, 2002). Further confusion has ensued related to the term Open Knowledge Initiative (OKI). The goal of the OKI (also affiliated with MIT) is to develop open architecture, technical standards, and sharable software to operate on different platforms for institutions to publish course materials on the net (Kumar, Merriman, \& Long al, 2001). OKI and OCW are seen as complementary efforts; OKI is the architecture, $\mathrm{OCW}$ is the repository of course materials.

\section{Managing the Digital Enterprise}

Managing the Digital Enterprise is an open courseware resource created in 1998 and maintained by Professor Rappa on servers located at North Carolina State University. The site is available free of charge to the public. http://digitalenterprise.org/ Evidence of the success of the site is indicated by the top-10 listing of corporate users, including Deloitte Touche, IBM, Eastman Kodak, Cisco, and Hewlett Packard. The university list of users includes over a hundred universities, including U.S. and international universities in China, Finland, Korea, United Kingdom, Canada, Mexico, Australia, and Chile. During his presentation in May 2001, Professor Rappa shared his experience of developing the site, including a discussion of the number of corporate and industrial partners who subsequently approached him when they found the site to be useful to their corporate training initiatives. Managing the Digital Enterprise has been of such sufficient use to some corporations that a number of them have been willing to provide funds to the project to ensure uninterrupted service.

Presently fifteen topics (chapters) are maintained on the site, with the web page for each topic having the same basic structure. The fifteen chapters include the following: introduction, navigating the web, digital design, web metrics, business models, digital markets, agents, auctions, channel conflict, trust in cyberspace, security and encryption, privacy, intellectual property, governance, and web ethics. For each of the aforementioned chapters, in addition to a short description of the subject, inclusive of stated learning objectives, there are several subsections accompanied by estimated times of completion that range from minutes to hours. The subsections include "things to read" which include several current articles, links to related materials, a frequently updated "in the news" section, "on the airwaves" for links to radio broadcasts, webcasted lectures by scholars and business leaders, and several other sections.

During June 2002, Professor Rappa made available seventeen case studies related to a majority of the fifteen chapters. These case studies are all related to actual organizations, with material available online, and the ongoing inclusion of related links, news articles, and academic studies. Questions are provided for each case to get students started in their analyses. Google, Lands' End, eBay, and Amazon are just a sampling of the cases available from the site. Per an email correspondence with Professor Rappa, his approach to the cases is "very much in keeping with the basic strategy of the course: i.e., rely on the Internet as the source" (Rappa, July 10, 2002). He also stated that the cases were a formalization of materials he had focused on each week in his traditional classroom lecture.

One benefit of Managing the Digital Enterprise compared to any of the myriad of websites useful to AIS education is the fact that adopting faculty can rest assured that selected articles for a given semester will remain accessible through the site for the duration of the semester. This is because the site provides the articles on backup servers in the event this material is removed from web sites from which it might have initially been obtained. Some of the articles are relatively short; others are the length of a typical chapter of a textbook. Many of the articles are in PDF format and thus require Adobe Acrobat Reader to access them. While the course material is promised to be accessible for the duration of a semester, this pledge does not extend to the nearly 1,000 links to external information sources. However, the integrity of all links is checked weekly by a web crawler, and the course site is updated continuously. In exchange for access to the course material, it is asked that acknowledgement by faculty who adopt this site be placed on course syllabus web pages. Professor Rappa emphasized during his presentation last May that he takes great care to select the material that is most useful, but he also is cognizant and respectful of copyright law. Sometimes the inability to obtain copyright for use of some potentially beneficial articles means that there is a tradeoff between what he might like to put out on the courseware site, and what he is actually able to. Professor Rappa, is a strong advocate of sharing knowledge openly and at no charge via the web. During the question and answer period of his plenary session, he acknowledged that more people had been exposed to his specialized research per- 
taining to business models available through this open courseware site, than would have been if the research were only published in traditional journal outlets. He is able to track this with various web metric techniques.

An instructor's guide, The Digital Professor, is available for Managing the Digital Enterprise at http://digitalprofessor.org. The aim of the instructor's site is to foster dialogue with faculty; in order to participate in the discussions, faculty must register. Upon registration, a login and password is provided via email. In the spring 2002 semester, The Digital Professor was brought online. This feature will prove very useful for AIS Educators to correspond on topics related to technology issues and teaching resources. Presently the site lacks a critical mass of users. However the call for papers section and faculty position openings appear to be active with postings added frequently.

\section{Semester 1 Integration with AIS Course}

During the Fall 2001 semester, the instructor concentrated primarily on the articles available through the Managing the Digital Enterprise site to include in the AIS course, since reliance could be placed that articles would remain accessible throughout the semester. Tentatively adopting the more traditional components of the courseware site allowed the instructor to gauge the overall student response to the site, without the experience of information overload. Accordingly, students were assigned their choice of eight of the fifteen chapters to independently complete an ongoing assignment using Webboard. The eight chapters for this semester long assignment included Introduction, Web Metrics, Digital Markets, Trust, Privacy, Intellectual Property, Internet Governance, and Web Ethics. Approximately $15 \%$ of the course grade related to the online discussion and interaction of students pertaining to the site materials. In addition, all students were required to read three other chapters that especially complemented the existing course text, and were used to supplement the face to face discussion of materials. These required reading materials included the Navigation chapter, which covered the basics of internet navigation addressed within the first week of the course, the Security and Encryption chapter, which was covered toward the end of the course, and the Agents chapter which was covered congruently with material on Artificial Intelligence.

The semester-long assignment was structured to be independently completed and not take class time. To accomplish this, Webboard, already being used for other aspects of the course, such as posting assignments and course-related links was used to facilitate student interaction and discussion of the material. For this assignment, students were required throughout the semester to post on Webboard, eight summarized reactions to articles included in their selected chapters. Students also were required to explore a minimum of eight links from the open courseware web site, posting the links on Webboard and briefly explaining to fellow AIS students why they found the links helpful. In an effort to prevent students from procrastinating, no more than one chapter reading was to be posted within a given week. To ensure diverse topical coverage as opposed to articles relating to only one chapter, no more than two articles from any one of these eight listed chapters were allowed to count toward an individual student's grade. About one-third of the total points allotted to the assignment related to students reading their peers' postings and providing their reactions and feedback. The plan was that material from the assignment would be tested in the same way the text and lecture material for the course was. The point of having students share reactions to the reading, was that students would not have to read every article in Managing the Digital Enterprise, but would reap the benefit of other students' selections and reactions.

While the student feedback to the assignment was very positive overall, logistically there were problems in the initial semester's attempt to incorporate the material into the course. These problems were not related to the Managing the Digital Enterprise course site, but rather to the implementation method using Webboard as the discussion forum. The first problem from the instructor's perspective, was that the assignment became very difficult to keep up with grading. While independent discussion forums were set up on the Webboard for each of eight assignments, it was difficult to monitor student postings, largely due to procrastinating students. Forums were checked every few weeks, but for the isolated students entering subsequent to the bulk postings, a monitoring device was necessary to ensure the postings were for different articles, since several weeks later it was hard to remember who had reacted to what. To achieve this purpose, an excel spreadsheet which acted as an assessment device was set up with details for each student, posted on the Webboard, and accessible to all. In this way students were able to review their own progress, as well as to note the instructor assessment for other postings. This also made it somewhat easier to find comments related to articles that were posted by students. The spreadsheet file included columns for an identification for each assignment by number from 1 to 8, date of posting, chapter and title of article, and three separate columns to indicate completion of the three deliverables, the article summary, posting of links, and reaction to 
peers. The overall quality of discussion was assessed in another column, using a tickmark legend that distinguished between a good or average student summary. In addition, further feedback was provided by means of a final column with comments to the students where merited.

Another problem pertained to channeling students onto similar topics. Because of the randomness with which students selected material to review and react, funneling discussion was next to impossible as students selected different chapters at different times. Thus the reading of material became tedious with a flow of disparate comments and much repetition. For example, some students posted from the Privacy chapter early in the semester in initial assignments; others would choose the same reading after midterm. Within the bulk of postings, reactions thus became lost; consequently the discussion flow was very disjointed, even though much of the discussion was related. The instructor realized that this flaw in instructional design likely deterred students from reading and reacting to the Webboard postings very efficiently. Consequently the subsequent testing of this material was determined to be problematic, and topics were not emphasized in testing, except for those topics specifically addressed in the face to face portion of the course.

From a more positive perspective, there was learning that occurred on the part of the instructor and the students that first semester. Several months after the close of the semester, several prior-semester students approached the instructor with questions about the open courseware site. One student had an interest in whether it was still being used the following semester and wondered why other professors were not using this kind of site. Another student commented that she returned to this site often to read the news articles, in order to stay current. She mentioned that she told one of her friends who could not find current materials on a particular IT topic to take a look at this site. She expressed her surprise that a computer science major did not know this resource was available, and how it made her feel good to be able to help someone find current materials so quickly and effortlessly.

\section{Semester 2 - An Improvement}

The Spring 2002 semester, it was decided that the funneling of students through the material required refinement. Rather than let students select chapters at random points, stand-alone modules encompassing two to three week periods were set up for selected chapters to be accessed, discussed, and reacted to. This change of incorporating five modules that ran the length of the semester substantially improved the process. Again eight chapters were selected in the following order for the course. Module 1 used the Introduction and Navigation chapters, Module 2 used Web Metrics and the Intellectual property chapters, Module 3 used Privacy and Web Ethics chapters, Module 4 used the Agents chapter, and Module 5 concluded with the Security and Encryption chapter.

The following material is taken from the Fall 2002course syllabus pertaining to the Managing the Digital Organization assignment requirements and the assessment criteria. Having learned from the prior semester, the instructor included an assessment rubric for use in clarifying assignment expectations and grading. The assignment continued to represent $15 \%$ of the final grade for the course.

"The output of increased IT learning is the aim of the assignment; therefore using Webboard, students will input and process thoughts. Students are required to post on Webboard, every two to three week module a brief explanation of something of interest to AIS students from assigned chapters of Managing the Digital Enterprise, as well as their personal reactions to items. In addition students are to respond to another student's posting. Finally in the last week of the module, a summarized reaction of at least one key item learned from the module is required. Material from Webboard postings will be subject to examination."

The following evaluation criteria were used for awarding up to 12 points for each module. The first part of the module focused on gathering data and processing it. The second part of the module focused on demonstration of attainment of learning, via the key item postings.

- Did the student submit in timely fashion?

- Was the comment clearly and succinctly written?

1 point

- $\quad$ Did the student express a concept in the comment?

1 point

- $\quad$ Did the student apply the concept in some way? (application to experience, the text, lec1 point ture examples, current events, business settings for managers and accountants, or by asking a penetrating, practical question) 
- $\quad$ Did the student critique another comment that they responded to?

1 point

- $\quad$ Did the student encourage others when posting comments?

- $\quad$ Did the student contribute more than expected?

For the key item posting, the following evaluation criteria will be used:

- Did the posting reflect critical thought, showing the student analyzed, dissected, and summarized related to a key item?

- $\quad$ Did the posting merely restate the student's or others' opinions?

- Did the student submit in timely fashion?

- Was the key item clearly and succinctly written?

After each module, the instructor provided written comments personally to each student along with grades using the aforementioned rubric, while "testable" topics related to the material were discussed briefly in class. A benefit of Webboard was the metrics provided from this software that indicate whether students are accessing discussion forums. While accessing the forum does not necessarily indicate that students are reading all comments, it was obvious that students were re-visiting the material. Earliest posted messages throughout a three-week period indicated that some messages had been accessed in excess of 150 times. Student messages that were posted late or right before the deadline, indicated fewer access attempts, for example, approximately 3 to 6 attempts. A second benefit of the online discussion was the diversity of topics discussed that otherwise would not have been allotted as much time in the course. For example, all of the following points were discussed in depth during the Module 3 discussion.

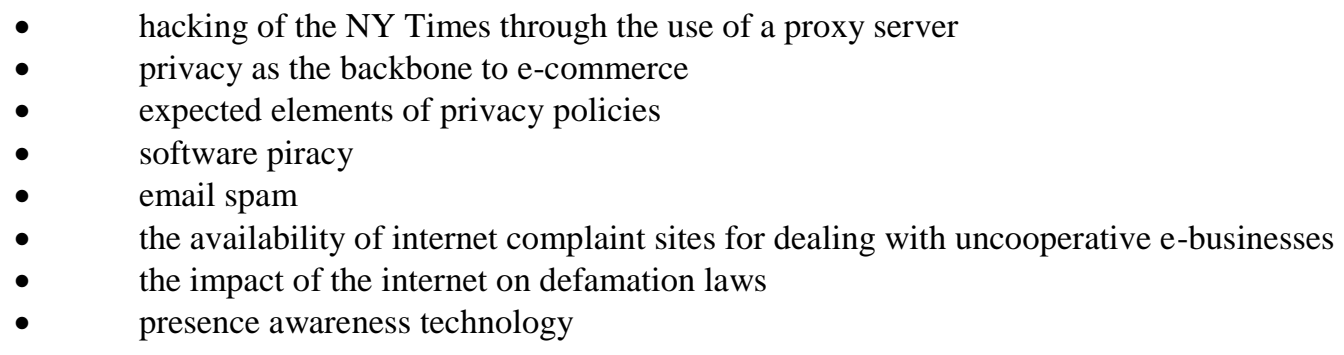

On several topics, students had emotional reactions to what they had learned, and expressed strong opinions; one example of this was evident in the discussion of presence awareness technologies - several students expressed that this technology frightened them.

Approximately two-thirds of the way through the course, student feedback about the assignment was obtained in the form of open-ended narrative comments. Out of fourteen students who responded, the vast majority replied that they liked the Managing the Digital Enterprise assignment for the following reasons:

"I like searching the internet for information. It helps my knowledge grow and my computer skills to strengthen. It helps to keep my interest more involved in the course."

"Learned more about technical topics that I thought I was already well-versed in."

"It pushed me to read and think on topics that I would not normally look at. I think it's expanded my understanding on AIS which is an area I've never really been interested in."

"Very current articles, which is very important with the expansion in the use of computer.s"

“A very interesting learning tool. I actually learned some stuff that I had no idea about."

"Since there was so much that I could go through but I didn't have to, I often spend a lot more time than I need to. While this could be seen as time wasted, I think it's good because I've never spend more time on homework actually absorbing more information before." 
Alternatively, there was only one student who responded that the courseware site was not useful. Some of the less positive comments about the site include the following.

“Mostly busywork, and I didn't actually learn very much from this website except about cookies."

"The main body of articles of the site were scant, and if you didn't read any of the links, then you didn't gain much more information."

"Some of the chapters were dry like the Agent chapter."

"The links were about 50\% quality and 50\% were too technical or academic for this course - the links were current."

There was a very mixed reaction to the mandatory postings to the Webboard, which reflects on the method of integrating the courseware material into an AIS course, and not on the Managing the Digital Enterprise itself.

"I do like the responsibility for posting to the Webboard, as I am not put on the spot to answer questions."

"Multiple posting about the same subject, even though it is tedious, still allows to pick up partial or relevant material missed in initial readings.”

"I like the Webboard setup, although initially a bit apprehensive of it."

"Almost too many messages to read on the same subject on Webboard."

"I liked seeing what the other students in the class pulled out of the reading material."

\section{Conclusion}

The intent of Professor Rappa in using the power of the Internet to learn about e-commerce is indicated when he states: "Rather than learn about e-commerce second-hand, in many instances you will go right to the source." (http://digitalenterprise.org/about/html) The comments of one AIS student appear to support this intent:

"When taking classes, it is easy sometimes to get behind with the reading material and sometimes even skip the reading material and just skim the chapters. With Managing the Digital Enterprise, I found myself reading the material and enjoying it. One reason for this is because while you're reading an article that you find interesting you may see a link for additional reading materials. This is how I found the majority of my articles that I submitted."

There is something exciting, even addictive, about having information available at the click of a mouse that merely turning the page of a textbook does not provide. It is uncertain whether this heightened interest of students is because the material is current and interactive, or because of increased engagement due to the involvement of multiple sensory inputs.

\section{Suggestions for Future Research and Teaching}

Continuation of the use of 'Managing the Digital Enterprise' in the AIS course is planned for future semesters. Continued experimentation with additional curricular elements of the site and their implementation within the AIS course with a goal of increased efficiency and effectiveness is merited. Attention to an appropriate percentage of the AIS course grade attributed to the resource is dependent on forthcoming decisions to be made.

Several potential adaptations appropriate to AIS educators are relevant. First, the cases recently added to the site are an obvious strength to any professor who wants to keep students focused on real world issues. Second, requiring students to participate at least once during the semester in a Webcast, guest lecture, or radio broadcast is reasonable; furthermore this would be beneficial to those students who have not previously used this technology. A third use could be having students report on the site's breaking news items several times a semester, either briefly in the face to face classroom, or online. 
A recent review of the courseware forum (discussion board) indicated a very high quality of remarks posted related to the subject of encryption and security. When queried as to whether the forums are open to all, Professor Rappa affirmed in an email communication that the discussion is open. However he pointed out that students may be working at different levels and he does not actively encourage instructors to channel their students to the forum. "The most important thing in creating a high level of conversation is to be sure students are reading assignments and offering informed opinions. Otherwise students may spam the board with random opinions, which is not helpful" (Rappa, July 9, 2002). One suggestion for forum use is to have students compare and assess the quality of postings by students at the other institutions with their own online course forum for a similar topic, posting their analysis online. This kind of peer review could substantially improve the quality of discussion for those students who are not at that high a level.

A final suggestion for interested AIS professors is that they register for the forum available at The Digital Professor site to allow ongoing discussion of matters related to teaching AIS. Professor Rappa plans in the Fall semester of 2002 to get the forum going and add online review exercises and exam questions. This reflects one of the primary strengths of open courseware. This site, and others like it, can engage AIS educators around the world in the discussion and sharing of similar interests, and build on one another's knowledge base. Especially in smaller institutions, the AIS educator often operates in an environment of isolation from colleagues with similar interests. Additionally the MIT OCW is slated to move beyond its initial pilot site access to releasing sites to the public in September 2002 (Project Updates, 2002). While it is presently uncertain whether course content related to an AIS curriculum is forthcoming at this time, it is beneficial to be aware of this possibility. The field of AIS is changing quickly, making it increasingly challenging to remain current. Checking in periodically in this open courseware project is one convenient and inexpensive tool that will help the AIS educator feel and remain connected to the discipline and to colleagues.

\section{References}

1. Kumar, M. S. Vijay, Jeff Merriman, and Phillip D. Long. "Building "Open” Frameworks for Education," EDUCAUSE Review, November/December 2001.

2. Long, Phillip D. “OpenCourseWare: Simple Idea, Profound Implications,” Syllabus Magazine, January 2002. Retrieved July 15, 2002 from the Syllabus Web Site: http://www.syllabus.com/syllabusmagazine/article.asp?id=5913

3. "MIT to Make Nearly All Course Materials Available Free on the World Wide Web," MIT News, April 4, 2001. Retrieved July 15, 2002 from the MIT Web Site: http://web.mit.edu/newsoffice/nr/2001/ocw.html

4. "OCW and What Does it Mean to My Campus?" TechTalk Transcript, March 7, 2002. Retrieved transcript July 15, 2002 from TechTalks Web Site: http://www.cren.net/know/techtalk/events/mit.html

5. Project Updates. Welcome to the MIT OpenCourseWare Information Home. Retrieved July 24, 2002 form the MIT OpenCourseware Information Home: http://web.mit.edu/ocw

6. Rappa, Michael. The Digital Professor: An Instructor's Guide to Managing the Digital Enterprise. Retrieved July 15, 2002 from Digital Professor Web Site: http://digitalprofessor.org

7. Rappa, Michael. Managing the Digital Enterprise. Retrieved July 15, 2002 from Digital Professor Web Site: http://digitalenterprise.org 
Notes 